\title{
De las potencias políticas del neobarroco latinoamericano
}

\author{
Alejandra Adela González ${ }^{1}$ \\ UBA-UNDAV \\ alejandra.adela.gonzalez@gmail.com
}

Recibido 22/06/2018

Aprobado 24/08/2018

\section{Resumen}

El artículo parte del análisis de Mi tío el yaguareté de Joao Guimaraes Rosa, autor emblemático de la literatura brasileña. Se lo inserta en el neobarroco por sus condiciones estilísticas y enunciativas, pero el análisis que intentamos realizar aborda, desde una óptica filosófica, los efectos ético políticos de la narración a partir de su cruce con perspectivas etnográficas como la de Viveiros de Castro, que releen a Claude Levi Strauss tomando en cuenta categorías de Giles Deleuze y Félix Guatari. Así las nociones de sujeto, objeto, persona, lengua y las diferencias entre géneros, razas o especies se desestabilizan a partir de las consideraciones del perspectivismo amerindio y de las concepciones canibalísticas de la metafísica.

Palabras clave: Neobarroco-perspectivismo-canibalismo-multinaturalismo-filosofia política

\section{Abstract}

The article departs from the analysis of Mi tío el yaguareté of Joao Guimaraes Rosa, emblematic author of the Brazilian literature. It is inserted in the neobarroco by

\footnotetext{
${ }^{1}$ Doctora en Filosofía (Universidad del Salvador) con la tesis "Voluntad de servidumbre y deseo de libertad. Una paradoja política en Simone Weill y Etienne de La Boètie" (Tercer Premio nacional de Ensayo Filosófico, 2012). Magister en Análisis del Discurso (Universidad de Buenos Aires). Actualmente es docente e investigadora de la Universidad de Buenos Aires, de la Universidad de Avellaneda y de la Universidad del Salvador. Coordinadora Académica de la Maestría en Estéticas Contemporáneas Latinoamericanas de la Universidad de Avellaneda. Autora de varios libros y numerosas publicaciones en el campo de la filosofía política
} 
his stylistic conditions, but the analysis that is realized approaches, from a philosophical optics, the effects ethical politicians of the story from his crossing with ethnographic perspectives like that of Viveiros de Castro, which read to Claude Levi Straus bearing in mind categories of Giles Deleuze and Félix Guatari. In consequence, the notions of subject, object, person, language and the differences between kinds, races or species are destabilized from the considerations of the Amerindian perspectivismo and the conceptions "canibalísticas" of the metaphysic.

Keywords: Neobarroco-perspectivism-cannibalism-multinature-political philosophy

Nos proponemos desplegar los efectos de sentido ético políticos de un texto enmarcado en el neobarroco. Nos interrogaremos a partir de la lectura de algunos fragmentos de Mi tío el yaguareté ${ }^{2}$ de Joao Guimaraes Rosa ${ }^{3}$.

Desde el cruce de las miradas hasta la asimilación con el otro o del otro, ciertas perspectivas de un barroco de la contraconquista, al decir de Lezama Lima ${ }^{4}$, se presentifican en operaciones lingüísticas específicas. Tales esos quiasmos que vuelven invisible lo visible y viceversa, disuelven todo realismo representacional, y cuestionan las nociones clásicas de sujeto y objeto. Un cazador mestizo que se vuelve jaguar o un brujo que se transforma en halcón no son más que las formas de ese travestismo, disfraz, paradojas del engaño, que tornan a la superficie barroca en una instancia de topologías ambiguas. El modo en que lo verdadero se deduce de esas ficciones es la matriz desde la cual esas figuras literarias dan que pensar. Cuestionamiento de la realidad y de la verdad, multiplicación alucinatoria de fragmentos textuales, devenir de las lenguas, trasformaciones de la significación por su abordaje corporal, superposición y mímesis como puesta en abismo, son estrategias de construcción de universos

\footnotetext{
${ }^{2}$ Guimaraes Rosa, Joao. (2002) Campo general y otros relatos. México, FCE.

${ }^{3}$ Joao Guimaraes Rosa nacido en Minas Gerais en 1908, muerto en Río de Janeiro en 1967. Es considerado uno de los autores emblemáticos de la literatura de Brasil y constructor de un portugués propio de la región, propulsor del modernismo, y marca del neobarroco brasileño regionalista. Cf. Rubén Bareiro Saguier en Encuentro de Culturas, Emir Rodriguez Monegal, Rupturas de la tradición, Severo Sarduy, El Barroco y el Neobarroco, Jorge Enrique Adoum, $n$ El realismo de la otra realidad, Haroldo de Campos en El lenguaje de la literatura, Amétrica Latian en su literatura, (1972) Mexico, Siglo XXI. Luz Angela Matínez,(2009) Barroco y neobarroco. Del descentramiento del mundo a la carnavalización del enigma. Chile, Editorial Universitaria. Champi Irlemar, Barroco y modernidad. (2000) México, FCE.

${ }^{4}$ Lezama Lima, José. (2014) Cf. La curiosidad barroca en Ensayos barrocos. Imagen y figuras en América Latina. Buenos Aires. Colihue
} 
multiformes, siempre en expansión, siempre críticos de todo carácter hegemónico del significado y del poder unificante.

A Mi tío el yaguareté se lo ha ubicado en el neobarroco brasileño por consideraciones estilísticas, enunciativas y temáticas ${ }^{5}$. Pero nuestras reflexiones proceden más bien de una tradición hermenéutica que ahonda las tensiones en la interpretación al punto de romper con las estructuras gramaticales, y más allá aún, las diferencias genéricas: géneros literarios, sexuales, identitarios. Así se pone en juego la relación entre especies: humana, animal, hombre y jaguares, entre razas: mestizo, negro, blanco, indígena, entre identidades sexuales: varón/mujer jaguar, entre espacios: selvático/urbano, frontera entre oralidad y escritura, entre lenguas: portugués/tupí, entre palabra articulada y sonidos. Estas composiciones, ¿no son, quizás, una especie de descomposición? ¿No señalan una inestabilidad constitutiva de razas, idiomas, géneros y espacios?

Nos detendremos un momento en el plano de la lengua. El texto, de dificilísima traducción trabaja en dos niveles de descomposición: Por un lado, es un texto que se debe leer en voz alta. No basta con realizar una lectura silenciosa. Como Finnegans Wake de Joyce requiere la escucha atenta de una voz. Ahí ya se da un primer nivel de desestabilización: no puede establecerse una frontera nítida entre lo escrito y lo hablado, no respeta las normas de una lengua escrita sino que las marcas de la oralidad van socavando el límite. Se superpone a esta inestabilidad, una segunda: el texto está escrito en el portugués de un mestizo que lo interfiere con términos del tupí. Podríamos comprender este proceso desde la glotopolítica en tanto estudio de las relaciones de poder entre lenguas. ${ }^{6}$ Un concepto como el de glotofagia da cuenta

\footnotetext{
${ }^{5}$ Sarduy Severo. El barroco y el neobarroco en Sarduy, Severo. Obra completa. Edición crítica de Gustavo Guerrero y Francois Wahl, Madrid: Círculo de Lectores; Colección Archivos, 1999.Buenos Aires, siglo XXI. "En la exuberancia barroca de Gran Sertón: veredas, de Joao Guimaraes Rosa, son detectables, como sostenes oratorios, los dos procedimientos antes mencionados, pero fundidos en una misma operación retórica : el significado « Diablo » ha excluido del texto toda denominación directa _sustitución_; la cadena onomástica que lo designa a lo largo de la novela -proliferación- permite y suscita una lectura radial de atributos, y esta variedad de atribuciones que lo señala va enriqueciendo, nuestra percepción ... » (p.172)

${ }^{6}$ Calvet Louis-Jean (2005) Lingüística y colonialismo. Breve tratado de glotofagia

Buenos Aires, FCE, 2005. 1o ed. Paris, Payot, 1974 y en Las politicas linguisticas (1997) Buenos Aires, Edicial. Calvet define a la política lingüística como la demarcación de los campos de intervención humana en las lenguas. Es así que plantea las nociones de planificación linguística a partir de las operaciones estatales, jurídicas o institucionales destinadas a controlar las formas de producción del lenguaje escrito u oral. Pero especialmente se dedica a las maneras en que los procesos colonizadores
} 
del proceso por el cual una lengua devora a otra. El portugués fue la lengua imperial que abolió diferencias en Brasil a partir de la conquista, proceso que culminó con la institucionalización de la lengua portuguesa como idioma nacional, aun cuando esta determinación se tomó cuando la mayoría de los habitantes no hablaban esa lengua. Y en este cuento, el fluir de la lengua (¿de la conciencia?) es interrumpido por el tupi, el idioma ágrafo de los caníbales tupí nambá. Los feroces salvajes de la tradición completamente aplastados y reducidos a lugares ocultos de la selva, van interfiriendo con su voz en el largo monólogo de este personaje. ¿Lo hacen solo desde la incorporación de toponímicos, de vocabulario a nivel semántico, o se da porque la estructura gramatical, es decir, el modo de pensamiento, es más bien tupí y usa el vocabulario del conquistador?

El paralelismo con el mestizaje del narrador es evidente: Hijo de padre blanco y de madre indígena. Incierta la relación entre ambos, ¿violación, convivencia?, incierto el origen, la nacionalidad del padre, la etnia de la madre, que lo cría como los jaguares hembras a sus cachorros. Pero así como la lengua tupí va emergiendo poco a poco en el relato vertido en la lengua oficial del Brasil, se va infiltrando la voz materna oculta que aparece como un relámpago cada vez más potente en la superficie mestiza de la narración del cazador. Pero todavía más más allá de los conflictos idiomáticos, la fragilidad se descalabra por completo cuando la lengua oral en términos de sonidos guturales, onomatopeyas, descomponen el sentido hasta volverlo puro fonema. Sonido inarticulado frente a la doble articulación del lenguaje. El texto final termina en silencio. Una figura última, la del silenciamiento de todo sonido.

Conmovedora experiencia de lectura: recorrer el texto sin acudir al glosario que fue agregado en ediciones posteriores a la original, y cuya justificación se basa en que el tupi es una lengua muerta. ¿Quién no entiende el tupí? El blanco que irrumpe en la selva pero también el lector silencioso que somos. Alguien sabe más de lo que está escrito que el propio lector. Inestabilidad entre saber y no saber también. Se corre la frontera: ignorante es el que lee. O el blanco que no maneja más que una lengua, la 
portuguesa. No el mestizo que sabe el idioma de su padre, de su madre y también el del jaguar. "Yo yaguaricé." “iApé! Bueno, bonito. Yo soy jaguar.... iYo ----jaguar!””

El yo que acompaña todo enunciado se vuelve fluctuante y esquivo, y se desliza deshaciéndose en una narración donde hay una sola voz, que incluye las intervenciones del interlocutor, por la espacialidad de la página desde un renglón de diálogo en el comienzo hasta el final con los gruñidos del jaguar.

—¿Hum? Eh-eh... Sí. Sí señor. A-ha, si quiere entrar, puede entrar... Hum, hum... ¿Usté sabía que yo vivo aquí? ¿Cómo lo supo? Hum-hum... Eh. No señor, n’t,n't... ¿Su caballo, solo ése? ¡Ichi! El caballo ta manco, aguado. Ya no sirve. Achi... Pues sí. Hum, hum, ¿Usted vio este fueguito mío, de lejos? Sí. Ah, pues. Pase, usté se puede quedar aquí.

Pero no se trata solamente de la descomposición de la lengua, sino también de la identidad. El personaje mestizo, lo cual le da cierta ambigüedad en el origen, recibe diversos nombres: Bacuriquirepa, Breó, Beróm Toñito, Antonio de Jesús, Toño Tigrero, Macuncozo, Marupiara. No puede afincarse en ninguno, no responde más que por momentos a lo que cada uno de ellos convoca. Indio, devenido mestizo, quizás más por el oficio que por el linaje, vuelve a la selva, renuncia a la vida urbana, y se va adentrando en ella. Abandona su condición de cazador de jaguares, lo que le daba un status en la ciudad de los blancos, para retornar "adentro", enamorarse de María la mujer jaguar, y volverse paulatinamente el animal al que perseguía. Lógica del cazador cazado. Devenir animal de lo humano. Disipación de una diferencia, la de naturaleza y cultura, que solo adquiere potencia desde el pensamiento eurocéntrico pero que es desconocida para la perspectiva amerindia. Es lícito introducir la noción de perspectivismo propio de los pueblos amazónicos, tal como la plantea la antropología de Viveiros de Castro ${ }^{8}$. Las consecuencias filosóficas de esta noción implican el fin de

\footnotetext{
${ }^{7}$ Guimaraes Rosa, Joao. Mi tió el yaguareté, op cit. Pág. 411

${ }^{8}$ Viveiros de Castro Edoardo. La mirada del jaguar. Introducción al perspectivismo amerindio. (2013) Buenos Aires, Tinta Limón. “... la mitología de los pueblos amerindidos afirma que en el comienzo de los tiempos animales y humanos eran una sola cosa (mejor dicho, una "sola Cosa" múltiple: continua y heterogénea a un mismo tiempo), y que los animales son ex humanos, no que los humanos son ex
} 
la separación sujeto objeto, y más todavía, cuerpo-máquina alma-racional. Al contrario de la posición de la cultura blanca occidental, aquí hay un continuum, y la división categórica entre animal y humano se desvanece en una frontera lábil. De allí el peligro de habitar en la selva. No es bueno que el hombre vaya allí sin estar acompañado. La mirada del jaguar o la del halcón puede capturarnos al punto de que el brujo o el chamán no puedan volver a su cuerpo humano. Es lo que sucede con el protagonista de nuestro cuento. Identidades diaspóricas, entonces, que no permiten fijezas de razas o de lenguas. No es que no se perciban las diferencias, el narrador habla del negro con quien compartió su choza, de su interlocutor blanco, de su madre india. Pero él mismo fue del mestizaje al indio y del indio al jaguar en una continuidad pasmosa que no se ancla en categorías.

¿Usté cree que parezco jaguar? Hay horas que parezco más. Usté no ha visto. Usté no tiene aquello -espejín, ¿̇endrá?. Quería ver mi cara... Tiss, n’t, n’t...Yo tengo la mirada fuerte. Eh, hace falta saber mirar el jaguar, encarado, mirar con coraje, ha, él lo respeta. Si usté ve con miedo, él sabe, usté entonces ta perdido. No puede tener miedo. El jaguar sabe quién es usté, sabe lo que está sintiendo. Eso yo lo enseño, usté aprende. Hum. Él oye todo, ve todo movimiento. Rastrear, el jaguar no rastrea. No tiene buen olfato, no es perro. Caza con los oídos. El buey resopló en el sueño, rompió un pastito: desde media legua, el jaguar sabe... No señor. El jaguar no acecha desde lo alto del árbol. Sólo la suasurana salta arriba del árbol: la moteada no salta: la moteada sube derecho, como gato. ¿Usté ya lo vio? Eh, eh, yo trepo en árbol, acecho. Yo, sí. Espiar de allá arriba es mejor, nadie ve que estoy viendo...Deslizarme al suelo, para llega cerca de la presa, con quien mejor lo aprendí fue con el jaguar. Tan despacín que uno mismo no siente que avanza del lugar... Hay que aprender todos los movimientos de la presa. Yo sé cómo usté mueve la mano, que usté

animales.) p. 21 "El perspectivismo no es una forma de relativismo. Sería un relativismo, por ejemplo, si los indios dijeran (cosa que no hacen) que para los cerdos todas las otras especies son en el fondo cerdos aún cuando parezcan humanos, jaguares, yacarés, etc. .... Cuando digo que el punto de vista humano es siempre el punto de vista de la referencia queiro decir que todo animal, toda especie, todo sujeto que esté ocupando el punto de vista de referencia se verá a sí mismo como humano... incluso nosotros" (p.23) 
ve hacia abajo o hacia arriba, si hace falta ya sé cuánto tiempo le toma saltar. Sé en qué pierna usté se apoya primero.... ${ }^{9}$

La inestabilidad de la lengua, las razas, los géneros, se extiende al espacio. La selva es el lugar otro de la civilización. Es una casa, una hacienda, los que la habitan son vecinos. Nomadismo de un espacio que no está mensurado por la propiedad privada. Noción diversa de casa en oposición a todas partes. La casa selva es un espacio donde siempre se está yendo o viniendo, sin direcciones delimitadas.

Ha-ha. Esto no es una casa... Hubo. Creo que sí. No soy hacendado, soy vecino... Eh, tampoco soy vecino. Yo - por todas partes. Toy aquí, cuando quiero me mudo. Sí. Aquí duermo. Hum. ¿Ñen? Usté es el que habla. No señor... ¿Usté va yendo o viniendo ${ }^{10}$

Espacialidad diversa a la de los ejes cartesianos o la perspectiva renacentista. Ligado no a la jerarquía sino al peligro o el resguardo. "Si el perro se descuidó, la mano del jaguar le agarró por atrás, le rasgó toda su ropa... “11

El cuerpo es un ropaje, claro, porque todos hemos sido humanos en el origen, y ahora somos animales diversos. Y conserva el jaguar la crueldad del humano. Y el perro su laboriosidad. Identificacióne entre el modo de habitar y el modo de ser.

También sabía lo que el jaguar estaba pensando. ¿usté sabe en lo que piensa el jaguar? ¿No sabe? Eh, entonces aprenda: el jaguar sólo piensa en una cosa --que todo es bonito, bueno, bonito, bueno, sin toparse con nada. Nada más piensa eso, todo el tiempo, largo, siempre lo mismo, y así va pensando mientras camina, come, duerme, haga lo que haga...Cuando algo malo ocurre, entonces de pronto chirría, ruge, tiene rabia, pero no piensa en nada: en ese instante deja de pensar. Nada más cuando todo vuelve a estar tranquilo, piensa otra vez, igual, como antes ${ }^{12}$...

\footnotetext{
${ }^{9}$ Guimaraes Rosa, Joao. Mi tió el yaguareté, op cit. Pág. 424

${ }^{10}$ Guimaraes Rosa, Joao. Mi tió el yaguareté, op cit. Pág. 413

${ }^{11}$ Guimaraes Rosa, Joao. Mi tió el yaguareté, op cit. Pág. 427

${ }^{12}$ Guimaraes Rosa, Joao. Mi tió el yaguareté, op cit. Pág. 419
} 
Por eso el canibalismo no es la práctica de comer carne humana, ya que todos los animales de la selva lo son, sino simplemente de comer carne. Por lo que harán falta rituales para compensar la depredación que se realiza por el solo hecho de cazar. Es una práctica necesaria para la subsistencia, pero no pueden excederse de los límites. Y el animal cuando es cazado se encuentra con su cazador y se entrega a él. Diverso por completo de lo hecho por nuestro narrador que ha cazado al modo de los blancos: sin medida, solo para conseguir la piel. El conoce las estrategias de la caza porque puede identificarse con el animal y transitar de una piel a la otra, pero usó ese poder como un depredador blanco.

Eh, entonces daban dinero a quien matara a Pie-de-Olla. Yo fui. Hablaban de seguirle el rastro. Hum-hum... ¿Cómo podrían rastrear, encontrarlo rastreado? Yo andaba lejos...¿¿Cómo iban a poder? Hum, o. Pero yo sé. Yo no busqué. Me acosté en el lugar, olí su olor. Ya me vuelvo jaguar. Entonces me vuelvo jaguar de verdad, ah. Maúllo...Entonces supe. ${ }^{13}$

El final del relato no es sólo el de la muerte del narrador, también es la conversión en sonidos guturales propios del jaguar del idioma del conquistador puesto en boca de un mestizo. Fin de la ilusión de una posible fusión entre culturas. El choque civilizatorio, el genocidio no puede terminar en un mestizaje híbrido y pacificador.

¡Voltee ese revolver! No juegue, voltee el revolver para el otro lado..No me muevo, toy quieto, quieto... Oiga: ¿usté quiere matarme, ui? ¡Quite, quite el revolver para allá! Usté ta enfermo, ta desvariando... ¿Vino a llevarme preso? Ui: pongo la mano en el piso de casualidad, sin razón.. Ui, el frío... i¿Usté está loco?! ¡Atié! ¡Salgase, la choza es mía, cho! ¡Atimbora! Usté me mata, el compañero viene, se lo lleva preso... El jaguar viene, María-María se lo come... El jaguar es mi pariente.. Ei ¿por culpa del negro? No maté al negro. Taba contando tonterías ... ¡Miré el jaguar! Ui, ui, usté es bueno, no me haga eso, no me mate..Yo---Macuncozo.. No haga eso, no lo haga..Ñeñeñém... ¡Heeé!...

\footnotetext{
${ }^{13}$ Guimaraes Rosa, Joao. Mi tió el yaguareté, op cit. Pág. 428
} 
He...Aar-rrá...aaah..Usté

me

arahoou...

Remuancí...

Reiucaanacé...Araa..Uhm..Ui...Ui...Uh...Uh...eee. ${ }^{14}$

La transformación un hombre en animal no es nueva en la literatura contemporánea. Quizás el caso más emblemático sea el de La Metamorfosis de Franz Kafka ${ }^{15}$.

Una mañana, tras un sueño intranquilo, Gregorio Samsa se despertó convertido en un monstruoso insecto. Estaba echado de espaldas sobre un duro caparazón, y al alzar la cabeza, vio su vientre, convexo y oscuro, surcado por curvadas callosidades, sobre el cual casi no se aguantaba la colcha, que estaba a punto de escurrirse hasta el suelo. Numerosas patas, penosamente delgadas en comparación al grosor normal de sus piernas, se agitaban sin concierto.

-¿Qué me ha ocurrido?...16

Se trata de un hombre convertido en insecto por el acto de una exterioridad que no puede comprender. Este acontecimiento ha sido sometido a múltiples interpretaciones. No se trata de plantear una nueva, sino de pensar su diferencia con la "yaguarización" del mestizo. Ambos se insertan en dos tradiciones literarias y en dos culturas tan diversas que resultan inconmensurables. En la tradición de la literatura europea y bíblica a la que remite Kafka, el especismo es un punto de partida. No hay naturaleza de ninguna índole sino sufrientes humanos, doloridos sujetos, hombres y mujeres, amenazados siempre por el imperio de una historia que hace del mal su motor. Las catástrofes naturales son ínfimas frente al padecimiento que provocan las relaciones interhumanas. Pero se supone, además, que la humanidad, creada o no por un gesto trascendente, ha sido puesta frente a la angustia de su libertad, su culpa o la cobardía de su conciencia, independientemente de su vínculo con los animales. Estos, puestos por Dios en la naturaleza para servir al hombre, o

\footnotetext{
${ }^{14}$ Guimaraes Rosa, Joao. Mi tió el yaguareté, op cit. Pág. 446

${ }^{15}$ Kafka, Franz. La metamorfosis. Madrid, Alianza, 2011.

${ }^{16}$ Kafka, Franz. Op. Cit. Pág. 9
} 
víctimas de la concepción cartesiana que los vuelve máquinas incapaces de sentir, no operan más que como un paisaje de fondo, o en este caso, como el horror en el que cae un individuo desplazado de su lugar humano y atrapado en el cuerpo horrendo de una bestia. En Mi tío el yaguareté, al contrario, habría que leer cuidadosamente la cosmovisión amerindia, en la que el multinaturalismo y el perspectivismo decolocan la tradicional visión sujeto (humano) y objeto ( todo el resto de los entes en los que se incluye a los animales) para desmantelar una visión especista que necesariamente conlleva la superioridad de unos cuerpos sobre otros. Desde esta perspectiva, el pasaje de mestizo a indio y de indio a jaguar, habla más bien de un retorno a esa visión que no plantea jeraquizaciones ni superioridad, sino más bien la posibilidad de ser capturado en el juego de miradas, dentro de un mundo donde la caza equilibrada para la consecución de la vida, es la metáfora de las relaciones entre los seres bióticos y abióticos - discriminación que solo puede pertenecer al pensamiento occidental. El retorno al cuerpo del jaguar no es una caída estrepitosa en la exclusión y la muerte, sino al contrario, una reinserción en un ciclo vital del que el protagonista se había apartado por su oficio. Caza depredatoria ligada a la economía acumuladora del hombre blanco.

Metamorfosis no, entonces, sino mutaciones por diferentes cuerpos unidos por una mismo origen: en el principio todos habríamos sido humanos. Luego devenimos animales diversos. No hay evolución en pertenecer a nuestra especie.

La filosofía de la historia de Guimaraes no es optimista, la muerte viene de mano del blanco, contra un mestizo que ha vuelto a su etnia y a su espacio vital luego de haber abandonado y violentado sus fronteras. Ambos relatos terminan con la muerte violenta de sus protagonistas.

Derivas ético políticas del perspectivismo y el multinaturalismo: la persona como problema

Nos interesa tomar lo que puede cuestionar, en la perspectiva del multinaturalismo amerindio, una visión ético política no dualista, no centrada en el dominio jurídico ni en el ámbito trinitario del que se desprende la noción de persona, que se ha ido extendiendo a diversas instancias en el dominio del derecho liberal. Pero seria posible pensar modos de lo impersonal en metafísicas no occidental. 
Al respecto el planteo de cierta antropología que relee a Levi Strauss en las experiencias de convivencia con comunidades indígenas de la selva brasileña, aportan algunos conceptos que podrían ir en vías de un modelo de pensamiento que no se asiente en la ontoteología jurídica que se articula en el concepto de persona.

En primer lugar, parece necesario volver la noción de persona no un sustantivo es decir una sustancia, ni un adjetivo, es decir un predicado, sino una relación. Proponerse, de otro modo, que la noción de persona especifique un cierto tipo de colectivo, redes o relaciones que puedan denominarse personales. Quien puede preguntarse quién es persona, tiene garantizado ya el lugar de tal. ¿Cómo desmontar el artificio por el cual esta pregunta puede ser hecha? Otra vez, quien interroga, ya define la naturaleza o condición del otro. Así de inmediato se subjetiva quien pregunta y se hace objeto lo que es problematizado. Y el gran sujeto, será el Estado, las reglamentaciones jurídicas o el discurso hegemónico de la ciencia que legitiman o distribuyen identidades. Cuestionada la propia pregunta, nos queda decidir si alguien es persona en función de la autodeterminación realizada por los propios polos relacionales. Se trataría entonces de elucidar las condiciones de autodeterminación ontológica de aquel que aparece en el lugar del otro, del extraño. Y, más profundamente aún, poner en tela de juicio, las metadefiniciones que atribuyen el estatuto de persona o de persona no humana a los diversos entes.

Si se trata de suspender todo anclaje en sustancia alguna, en la estructura genética, en algún tipo de figurabilidad anatómica, o en la autoconciencia, o en la racionalidad, o en el contenido teológico del alma, se acentuará el carácter relacional de vínculos de proximidad, parentesco, vecindad que permiten contemplar dimensiones translocales de tales personas en una comunidad. Dimensiones entonces que implican lazos históricos o culturales con comunidades incluso ya aparentemente desaparecidas, estas relaciones puede ser de filiación adoptiva, de parentesco ritual o religioso, o en última instancia de ligaduras por afinidades. Esto permite el pasaje a una definición de persona ligado a un andamiaje político. No se trataría de la sangre, o el genoma, y sí tal vez de la comensalidad. El sentarse a la mesa como la aceptación de la proximidad del otro, su carácter de prójimo. O de cercanía en la territorialidad pensada como una superficie donde todos los que se traman en ella tienen carácter de 
persona por una posición a priori. Una especie de subjetivación distribuida, que no permite la centralización y solo lo periférico. Acéntrica en la definición, inidentificable con una cultura determinada. De otro modo, conversión o reversión del proceso de personificación (o su contradictorio) la cosificación. Más bien un discurrir interrogativo sobre el ser de persona, que se desliza más bien hacia la pregunta de la existencia del otro. Claro que esto implicaría una pérdida de la propia mirada como centro y un dejarse captar por la perspectiva de otro. Tal punto de vista implica diferencia. Entonces no se trata de demostrar que todos somos iguales en tanto personas, sino al contrario, que todos somos diferentes por el mismo motivo. No se trata de pensarse como sujeto en la ausencia de otro, sino ser pensado por otro como sujeto. Aspecto relacional que implica la presencia de los otros como única garantía de ser visto y, por lo tanto, de subjetivación. El punto de vista crea al sujeto para el perspectivismo amerindio. Lo que implica que el perspectivismo no es un relativismo. No se trata de que el punto de vista crea al objeto, sino por el contrario que crea al sujeto. El tema es evitar una noción de persona que se elabore junto con un sistema de la naturaleza, o una taxonomía que recopile aquellos capaces de entrar en un horizonte ontológico. Tal perspectivismo no es una selección ni una clasificación primitiva. El tema es que la perspectiva es lo que constituye esa relación en que nos personificamos para otro. El punto de vista es pura diferencia, por lo tanto es necesario ser pensado, deseado, imaginado, fabricado, por el otro para que la perspectiva aparezca como tal. Si hay un punto de vista exterior no puede definirse el estatuto ontológico autónomo. El sujeto no es quien se piensa como sujeto en la ausencia del otro, es quien es pensado por otro y frente a éste como sujeto. Modo de aproximarse a eso impersonal entonces, que Weil $^{17}$ requiere, en este abordaje tan peculiar que es el perspectivismo amerindio, otra de cuyas consecuencias filosóficas es la falta de un centro o lugar absoluto que unifique y armonice los potenciales puntos de vista. Claro que tales perspectivas son además interpretaciones, están ligadas a los modos de ver de cada especie, y necesarias para la afirmación vital de cada existente. Las perspectivas o interpretaciones nietzscheanamente consideradas son miradas o expresiones

\footnotetext{
${ }^{17}$ Weil Simone. La persona y lo sagrado. Archipiélago № 43/2000 Septiembre octubre. Allí se realiza una de las críticas más agudas al concepto de persona, planteando la noción de impersonal, como posible fundamentación de una teoría de lo viviente, cuestión que excede los límites de este artículo.
} 
parciales del mundo. Pero se trata de pensar desde el objeto pensado. Por lo tanto atribuir intencionalidad a todo. Contra el intelectualismo objetivante de la tradición occidental, no se trataría de probar la humanidad de cada vez más entes, es decir su condición de persona, sino de soportar la pura relacionalidad de una trama de diferencias que no se pueden unificar bajo ningún régimen. No pueden ser verdaderas todas las posiciones al mismo tiempo, lo que hace imposible toda comprensión de este relativismo como un multiculturalismo. No se trata de muchas perspectivas que pueden sumarse en una totalidad comprensiva o tolerante, sino de la condición relacional de fuerzas, no de las representaciones que tenemos de los otros, sino de las interpretaciones siempre disimiles, donde se puede enunciar solo que cada de ellas expresa la verdad de su lugar. Son incompatibles porque son especies diferentes. No se trata de unificar todo bajo el concepto de persona o de pensar las relaciones interespecies bajo otra lógica, donde aparezca la incompatibilidad extrema de todos los puntos de vista, su absoluta incomposibilidad. Más allá todavía, cómo pensar una antropología que se niegue a sí misma.

Pero para despensar la noción de persona, es necesario salir del binarismo sujeto-objeto. Para que considere al otro como tal, -¿por qué tendría que ser igual a mí?-, sería importante reconocer en el otro polo del vínculo, la absoluta diferencia. No se trata de multiculturalismo, sino de infinitas multiplicidades, incluso del reconocimiento de que la persona no es sino una diferencia consigo misma, por el paso del tiempo, por las diferentes perspectivas que la capturan. ¿Cómo cuestionar la propia condición de persona a partir de la diferencia multiplicante? No igualarlo, ni los chimpancés, ni las especies vegetales en peligro de extinción ni incluso los recursos naturales no renovables se puede constituir como personas. Pero la ontología occidental es una política personalista: si se promoviera la simetría se pondría en riesgo el lugar del poder de El gran definidor. Reflexionar sobre la diferencia que somos para el otro, y no de la diferencia que el otro significa únicamente, es un modo de impersonalizar los vínculos en la terminología weiliana. Pero como plantea Viveiros de Castro, no se trata solamente de disolver la relación sujeto objeto, y volver a todos sujetos, sino, como lo formula el perspectivismo amerindio, armar una superficie tensa donde todos podamos ser sujetos y objetos al mismo tiempo. Donde podamos intuir 
que el otro también nos piensa, y considera si podemos entrar en su perspectiva y de qué modo. El otro existe, entonces nos piensa ( como objeto), tal vez, aunque mientras lo pensamos los sujetos somos nosotros. Muy cartesianamente considerado.

Esta posición también implicaría descolonizar las categorías que venimos pensando. Y descolonizarlas es desteologizarlas. Personacentrismo es el concepto nodal de una dimensión ética que deviene siempre etnocéntrica y eurocéntrica. Ni unidad ni identidad pacifican. Quizás la cuestión sea salir de una ética monoteísta centrada en un Dios personal que personifica a quien escucha. Escuchar la voz de las cosas, no es decir que las cosas son personas, sino que son posiciones, en eso únicamente iguales a nosotros. Si las relaciones no se sustancializan, entonces, no hace falta definir a los entes, sino relacionarse con ellos, es decir con lo diferente. El caso es que la ficción de la persona, es decir, su sustancialización, terminó devorando la trama de relaciones para hacer de ellas meras articulaciones contingentes. Contra la sustancialización y la unicidad, las definiciones fijas, y la ampliación indefinida de atributos, tal vez sería posible instaurar una cierta multiplicidad accesible para todo existente que nos permitiera aparecer en nuestra diferencia con quien nos vinculamos, sin determinar primero a qué especie pertenece. Nos queda por pensar, si eso que es puramente relacional resuelve el problema de lo impersonal, es decir lo sagrado del cada quien que solo puede ser percibido si nos vinculamos con ese otro cuya definición desconocemos, y que nos vuelve un enigma para nosotros mismos.

El perspectivismo amerindio es un concepto una forma de pensamiento, es otra imagen teórica de la teoría. No se trata de construir el punto de vista del indígena para englobarlo finalmente en el punto de vista del observador. El perspectivismo propone simétricamente, descubrir qué es un punto de vista para el indígena, cuál es el punto de vista presente en las culturas amerindias, cual es el punto de vista indígena sobre el concepto antropológico de punto de vista. El concepto indígena de punto de vista no coincide con el concepto de puno de vista del indígena, del mismo modo que el punto de vista del antropólogo no puede ser el del indígena ( no hay fusión de horizontes) sino el de su relación (perspectivas) con este último. Esa relación es de dislocación reflexiva. El perspectivismo amerindio sirve para contraanalizar antropologías que nos parecen demasiado familiares. Y que basan la función del 
conocimiento en representaciones proposicionales e identifican la facultad de pensar con el sistema del juicio, como si fuera la única manera de conocer. Es una imagen del pensamiento y no un punto de vista en el sentido tradicional. El concepto como subsunción de lo particular bajo lo universal.

Desde esta perspectiva amerindia, queremos trabajar la figura del canibalismo que aparece en el cuento en términos de devoración. Este es un neologismo ligado al descubrimiento del nuevo mundo. Es un tropo fundamental en la definición de la identidad cultural latinoamericana que delimita el espacio de diferencia colonial. Así canibalismo y América se homologan. Pero también canibalismo y cuerpo monstruoso, salvajismo, canibalismo y fealdad, sexualidad obscena. Es un tropo que provoca siempre el temor a la disolución de la identidad. Bajo la figura del caníbal se conceptualiza la diferencia con el otro previo a la civilización (europea). El esquema de la colonización imperial impone la construcción del caníbal. O de otro modo este tropo es la contrapartida necesaria de la modernidad-colonialidad ${ }^{18}$.

La genealogía del caníbal es el equivalente a una variación semántica sobre el tropo. Esa identificación entre canibalismo y América es el sentido necesario para la justificación del etnicidio. Por eso es necesario realizar un estudio tropológico sobre la retórica de la colonialidad y de su funcionamiento ideológico. No se trata de la verdad o falsedad histórica del canibalismo, sino de sus efectos en lo real. Instancia semiótica y no historización de un proceso. El canibalismo puede ser entendido entonces como un dispositivo político para producir una figura que necesariamente debe ser abolida.

\footnotetext{
18 Este concepto proviene de la teorización propuesta por Aníbal Quijano, el pensador peruano, fundador de la teoría de la descolonialidad. Cf. Colonialidad y modernidad/racionalidad en Perú Indígena, vol.13, no 29, Lima, 1992 . En Colonialidad del poder, eurocentrismo y América Latina en Aníbal Quijano. Textos de fundación. Buenos Aires, Ediciones del Signo define la noción de modernidad colonialidad como: "El hecho de que los europeos imaginaran ser la culminación de una trayectoria civilizatoria desde une estado de naturaleza, les llevó también a pensarse como los modernos de la humanidad y de su historia, esto es, como lo nuevo y al mismo tiempo lo más avanzado de la especie. Pero puesto que, al mismo tiempo, atribuían al resto la pertenencia a una categoría, por naturaleza, inferior y por eso anterior, esto es, el pasado en el proceso de la especie, los europeos imaginaron también ser no solamente los portadores exclusivos de tal modernidad, sino igualmente sus exclusivos creadores y protagonistas. Lo más notable,,, es que el hecho de que fueran capaces de difundir y de establecer esa perspectiva histórica como hegemónica del nuevo universo intersubjetivo del patrón mundial de poder". (P.116-7). De este modo, se habría establecido por primera vez un Sistema mundo global asociados a la colonización de Africa y América, es decir a su invención como territorios y poblaciones subordinados. Si bien siempre hubo imperios coloniales, el actual que inaugura la modernidad que comenzó hace quinientos años, tiene tres elementos que lo caracterizan: " la colonialidad del poder, el capitalismo y el eurocentrismo" (p. 120)
} 
De otro modo, es un sistema de presentación de la otredad, ligados a mecanismos de supresión, negación, represión. La figura del caníbal es sobreimpresa sobre la otredad fáctica para incorporarla a una secuencia de significantes: américa lúbrica, amazonas devoradoras de hombres, brujas, sexualidad satánica, monstruosidad natural. Pero para producir esta cadena, primero es necesario denominar, como verbo del poder, a eso "América". Significante de lo que no sabe, no es, no tiene historia, ni ser. América vacía es convertida en una vasta extensión natural. Esta denegación permite la consideración de América como un desierto o una página en blanco donde deben ser escritas, marcadas, las letras de la civilización. Por ese vaciamiento geográfico y la invención de una proliferación natural sin hombre, puede erigirse el personaje conceptual, figura de la otredad, sin lengua, sin pasado ni historia, pura devoración en un continuum espacial, donde el cazador y la pieza de caza terminan identificándose. Así el salvaje temido se vuelve odiado y por eso objeto de exterminio. Esa amenaza de la diferencia indomeñable se vuelve justificación ideológica de las masacres. Desde los tahíbes o cahíbes del diario de Colón, hasta el Calibán de la Tempestad de Shakespeare, se describe a estos caníbales como monstruosos, brutales, sin lengua, con instintos sexuales agresivos sin lengua, cuerpo máquina para el trabajo, si sobrevive al exterminio o no cae muerto por las epidemias dada su intrínseca debilidad. Sobre ese discurso de la denegación, se construye al caníbal como una etiqueta que se aplica al otro americano. La autoridad del enunciador es la que legitima la etiqueta a partir de una realidad imaginaria que no ofrece fisuras discursivas. Incluso la etnografía se construye como un saber sobre el otro donde se lo organiza en torno a prácticas culturales juzgadas como repudiables. Lo americano aparece así como el resultado discursivo de la asimilación teológica de la semejanza en el campo del mal y la monstruosidad moral. Para dominar a ese salvaje es necesario representarlo, cartografiarlo para finalmente abolirlo.

Frente a estos dispositivos retóricos discursivos hay dos posiciones extremas de un arco posible: una es plantear la inexistencia del canibalismo y marcarlos solo como invenciones coloniales para no hacerse cargo del horror abierto en América. Ese es el argumento de William Arens ${ }^{19}$ quien sostiene que, a su entender, el canibalismo ha

\footnotetext{
${ }^{19}$ Arens, William. The Man-eating Mith Anthropology and Anthrophagy. New York: Oxford U.P, 1979.
} 
sido inventado por los antropólogos y etnógrafos. Aquí se buscaría marcar como ese concepto, responde a una posición ideológica y al positivismo que está en la mancha original de las ciencias humanas, culpa propia de la empresa colonial. La posición de Arens fue defenestrada rápidamente por antropólogos y cientistas sociales para quienes la evidencia del canibalismo era irrefutable. Pero en esta polémica se trataba de decidir si fácticamente se practicaba la antropofagia y no de la efectividad en lo real de un tropo discursivo. En el otro polo, podemos situar el planteo de Viveiros de Castro $^{20}$. Describe una filosofía política indígena del canibalismo, en tanto autodeterminación recíproca por la incorporación del punto de vista del enemigo. Allí lo que se come de la víctima es el signo de su alteridad y esa alteridad se devora como punto de vista sobre sí. De tal manera inmanencia y trascendencia coinciden. El sacrificio entonces es entendido como un dispositivo teológico político. Viveiros recorre la mutación del canibalismo humano de los tupí al canibalismo divino de los arawaté que se refiere a la traslación de perspectiva que afectaban las funciones y valores de sujetos y objetos. El canibalismo póstumo de los arawaté funciona como un dispositivo místico funerario en tanto transformación estructural del canibalismo bélico sociológico. Mientras el tupinamba implica la captura, ejecución y devoración ceremonial del enemigo, el arawate plantea la predación como afinidad. En este discurso, el canibalismo suscita propensión metafórica y nomadismo semántico en la medida en que vira de la inmanencia a la trascendencia, rompe con el especismo, plantea un continuum natural, y rompe con la noción clásica de objeto y sujeto. El sujeto devorador asume el punto de vista del objeto devorado, para verse a sí mismo a través de los ojos del enemigo.

Pero, para nosotros, no se trata de averiguar si los tupinamba o los cahíbes eran realmente antropófagos, ni de llegar a un juicio de tipo moral o político sobre la pertinencia de tal práctica social, o debatir sobre la legitimidad de las hermenéuticas diversas que se requieren para dar cuenta del sentido de datos difícilmente clasificables con las mismas tipologías. Dado que tales acontecimientos son hechos de lenguaje y nos llegan por medio de memorias, diarios, documentos oficiales, bitácoras, sermones, etc, ¿no sería mejor plantear que es la misma estructura lingüística la que

\footnotetext{
${ }^{20}$ Viveiros de Castro , Edoardo. Metafísicas Caníbales. Madrid, Katz, 2010
} 
debe permitirnos explorar la eficacia social de una práctica, la constitución de un sentido, la pertinencia de una metáfora? El problema que nos preocupa es, entonces, cómo, por la vía de este tropo, el "canibalismo" de "América" entra en el imaginario europeo.

Una figura retórica que como tal da cuenta de la aparición en el campo discursivo de las formas de la subjetivación de esos otros: los oriundos de las Indias. La contrapartida de los indios que se rebelan, guerreros sanguinarios y antropófagos, son los indios mansos que se someten (y aquí toda otra genealogía que no explayaremos, la del buen salvaje). Estas dos formas de aparición discursiva delimitan el espacio de dos existencias. Acusados de antropófagos o justificados a lo sumo en el canibalismo ritual (por sus acusadores, una bien organizada sociedad teofágica), los cahíbes o los tupi, tendrán que hacerse un lugar en la historia a través de este montaje de una figuración que los contiene y les permite aparecer bajo la forma que el Imperio y su lengua le adjudican. El canibalismo es más que un argumento o un lugar narrativo, es una figura retórica en tanto espacio de aparición, el pasaje a lo público de la resistencia en América. Lo que se permite que pase de la condición de cuerpo vivo a la lengua, es apenas un residuo y se llama antropofagia. Pensar el canibalismo desde América implica entonces un problema semántico, una articulación discursiva pero sobre todo una posición epistémica. Quién sea definido como caníbal es una decisión política a tomar. Nuestra américa neobarroca desestabiliza representaciones, identidades, géneros, sujetos y objetos en políticas que tocan lo real más allá de las muertes que la fundan. 


\section{BIBLIOGRAFÍA}

Arens, William. The Man-eating Mith Anthropology and Anthrophagy. New York: Oxford U.P, 1979.

Guimaraes Rosa, Joao. Campo general y otros relatos. México, FCE,2002. .

Kafka, Franz. La metamorfosis. Madrid, Alianza, 2011.

Viveiros de Castro , Edoardo. Metafísicas Caníbales. Madrid, Katz, 2010

Viveiros de Castro, Edoardo. La mirada del jaguar. Introducción al perspectivismo amerindio. Buenos Aires, Tinta Limón, 2013.

Deleuze Gilles y Guatarí Felix. El Antiedipo. Buenos Aires, Madrid, 1985.

AAVV, 2004.Glauber Rocha. Del hambre al sueño, MALBA, Buenos Aires, ANCESCHI, L. (1984) L'idea del barocco. Bologna: Nuova Alfa.

ARCINIEGAS, G. (1975) América en Europa, Buenos Aires, Sudamericana, (1963) Biografía del Caribe. Buenos Aires, Sudamericnaa,

ARGAN, G. C. (1987) Renacimiento y Barroco, Madrid: Akal.

AVELLAR, J. (2002) Glauber Rocha, Cátedra, Madrid,

-----------(1995) A Ponte Clandestina. Birri, Glauber, Solanas, García Espinosa, Sanjinés, Alea: teorias de cinema na América Latina, Edusp/Editora 34, São Paulo/Rio de Janeiro

BAJTIN, M. (2002) Estética de la creación verbal. Buenos Aires: Siglo XXI. (1997) Hacia una filosofía del acto ético. De los borradores. Y otros escritos. Barcelona: Anthropos.

BENJAMIN, W. (1990) El origen del drama barroco alemán. Madrid: Alfaguara.

CALABRESE, O. (1987) La era neobarroca. Roma-Bari: Laterza. 
CARPENTIER, A. (1976) Tientos y diferencias. Buenos Aires: Calicanto.

CULLEN, C. (1986) Reflexiones desde América I. Ser y estar: el problema de la cultura. Buenos Aires: Fundación Ros.

CHIAMPI, I. (2000) Barroco y modernidad, Fondo de Cultura Económica, México,

DE CAMPOS, H. (2000) De la razón antropofágica y otros ensayos, Siglo XXI, Madrid.

DELEUZE, G. (2005) La imagen-tiempo. Estudios de cine 2, Paidós, Buenos Aires.

(2005) El pliegue. Leibniz y el barroco. Buenos Aires: Paidós.

ECHEVERRÍA, B. (1998) La modernidad de lo barroco. México: UNAM.

FERNANDEZ MORENO, C. (1979) América Latina en su literatura. México DF: Siglo XXI-UNESCO.

FUENTES C. (2012) La gran novela Latinoamericana. Buenos Aires, Alfaguara.

GADAMER, H. G. (1991a): Verdad y Método, Salamanca, Sígueme.

(1991b): Verdad y Método II, Salamanca, Sígueme.

GAMERRO, C.(2010) Ficciones barrocas, Eterna Cadencia, Buenos Aires.

LEZAMA LIMA, J. (1981) "La expresión americana”, en El reino de la imagen. Caracas: Biblioteca Ayacucho.

PAZ, O. (1985) Sor Juana Inés de la Cruz. Las trampas de la fe. México: FCE RICOEUR, P (1995a): Tiempo y Narración I. México: Siglo XXI. (1995b): Tiempo y Narración II. México: Siglo XXI. (1996) Tiempo y Narración III. México: Siglo XXI. 
-(2001): Del texto a la acción. Ensayos de hermenéutica II. México: FCE.

ROCHA, G. (2004) "Estética do sonho", em Revolução do Cinema Novo, Cosac Naify, São Paulo.

ROCHA, G. (1997) Cartas ao mundo, Companhia das letras, São Paulo.

SARDUY, S. (2011) El barroco y el neobarroco. Buenos Aires: Cuadernos del Plata.

(1974) Ensayos generales sobre el barroco. Buenos Aires:

Sudamericana

SAEZ RUEDA, L. (2009) Ser errático. Madrid: Trotta.

WEISBACH, W. (1944) Arte barroco en Italia, Francia, Alemania y España. Barcelona: Labor.

XAVIER, I, (1993) Alegorias do subdesenvolvimento: cinema novo, tropicalismo, cinema marginal, Editora Brasiliense, São Paulo. 